Session 2266

\title{
Design, Build and Test in a Thermal Fluids Laboratory Course
}

\author{
Robert Choate and Kevin Schmaltz \\ Western Kentucky University
}

\begin{abstract}
Mechanical Engineering students at Western Kentucky University are required to take a comprehensive thermal fluids lab in the fall semester of their senior year that is designed to augment the traditional thermal fluids engineering science courses taken during their junior and senior years. In addition to a variety of instructor-led thermodynamics, fluid mechanics and heat transfer experiments, student teams are required to design, build and test (DBT) an experimental design project of their own choice.

This project requires experimental problem solving skills, builds upon the analytical and numerical techniques they have acquired in their engineering science courses, and will then be expanded upon in a multi-disciplinary capstone laboratory design course in the spring semester of their senior year. The project is coordinated through the ME program Design of Experiments Plan and further supports the ME program's Professional Component Plan by requiring the use of engineering design with open-ended problems, integration of professional tools, and demonstration of professional communications. This experience takes place from a point of view that students are less familiar with the role of instructors building a lab experience. Secondary outcomes of the project include demonstration of professional ethics and teamwork with peer assessment.

This paper will review the experimental design projects implemented by the seniors, requiring the students to perform independent research and hopefully encourage lifelong learning. A number of ME program outcomes are supported by this activity and the assessment methods used and results gathered will be discussed.
\end{abstract}

\section{Introduction}

The Mechanical Engineering faculty at Western Kentucky University have used the development and implementation of professional experiences to provide consistent and properly assessed instruction for students pursuing the new baccalaureate Mechanical Engineering degree at WKU. To achieve these professional outcomes, of which experimental design is an essential outcome, it is necessary to provide students with the opportunity to acquire tools and skills, as well as technical competency ${ }^{1,2}$.

"Proceedings of the 2005 American Society for Engineering Education Annual Conference \& Exposition Copyright (C) 2005, American Society for Engineering Education" 
To provide students with the opportunity to expand their development in the area of thermal fluids experimental design, Mechanical Engineering students at Western Kentucky University are required to take a comprehensive thermal fluids lab (ME 420) in the fall semester of their senior year that is designed to augment the traditional engineering science courses

(Thermodynamics I and II, Fluid Mechanics, and Heat Transfer) taken during their junior and senior years. In addition to a variety of instructor-led thermodynamics, fluid mechanics and heat transfer experiments, student teams are required to design, build and test (DBT) an experimental design project of their own choice.

This DBT project requires experimental problem solving skills, builds upon the analytical and numerical techniques they have acquired in their engineering science courses, and will then be expanded upon in a multi-disciplinary capstone laboratory design course (ME 430) in the spring semester of their senior year. The DBT project is coordinated through the ME program Design of Experiments Plan and further supports the ME program's Professional Component Plan by requiring the use of engineering design with open-ended problems, integration of professional tools, and demonstration of professional communications ${ }^{1,2}$.

The ability of ME graduates to successfully design, conduct and analyze experiments is integrated across the ME curriculum. Beginning in the freshman year, students are provided with opportunities to acquire experimental, analytical and modeling tools and skills, and to develop effective means of communicating the results of their work. In an analogous fashion to the capstone design project providing a measure of the students' ability to perform a design project, the thermal fluids lab (ME 420) and capstone experimental experiences (ME 430) require that student teams demonstrate the application of experimental abilities to set up and analyze less-defined experimental problems. To assist in the organization of the thermal fluids lab and its assessment, the following six components have been used to define design of experiments $^{3,4}$ :

1. Experimental Planning

2. Methods of Measurement

3. Selection of Instrumentation

4. Analysis of Data and Results

5. Uncertainty Analysis

6. Reporting of Experimental Results

Student work from select experimentation courses is assessed through a rubric to determine the ability of the students to successfully apply each component. The ME 420 course provides students with instruction in all of these components and the opportunity to demonstrate proficiency. Table 1 summarizes the lab classes or classes with a lab component in the ME curriculum that encompass the Design of Experiments Plan and the components that are covered and that students are expected to demonstrate in the class. The highly structured lower division laboratories are used to introduce students to the use of laboratory measurement equipment, laboratory analysis techniques and reporting methods (components 2, 4 and 6). At the other extreme, unstructured upper division laboratories (ME 420 and ME 430) are delivered at the senior level requiring students to apply analysis and synthesis skills to design and to test a largescale or multi-component system ${ }^{2,6}$.

"Proceedings of the 2005 American Society for Engineering Education Annual Conference \& Exposition Copyright (C) 2005, American Society for Engineering Education" 


\begin{tabular}{|l|l|c|}
\hline \multicolumn{1}{|c|}{ Semester } & \multicolumn{1}{|c|}{ Lab Course (credits) } & Component Coverage \\
\hline \hline \multirow{2}{*}{ Freshman Fall } & CHEM 121 Chemistry (2) & 2,4 and 6 \\
\cline { 2 - 3 } & ME 241 Materials/Methods Mfg. Lab (1) & 2,4 and 6 \\
\hline Freshman Spring & PHYS 251 Physics I (1) & 2,4 and 6 \\
\hline Sophomore Fall & PHYS 261 Physics II (1) & 2,4 and 6 \\
\hline \multirow{2}{*}{ Sophomore Spring } & ME 200 Sophomore Design* & $1,2,3$ and 5 \\
\cline { 2 - 3 } & ME 331 Strength of Materials (1) & $1,2,4$ and 6 \\
\hline Junior Fall & STAT 301 Applied Statistics* & 4 and 5 \\
\hline \multirow{2}{*}{ Junior Spring } & $\begin{array}{l}\text { ME 310 Engineering Instrumentation and } \\
\text { Experimentation (3) }\end{array}$ & $2,3,4,5$ and 6 \\
\hline \multirow{2}{*}{ Senior Fall } & ME 411 Vibrations/Controls Lab (1) & $2,3,4$ and 6 \\
\cline { 2 - 3 } & ME 420 Senior ME Lab I (3) & $\mathbf{1 , 2 , 3 , 4 , 5}$ and 6 \\
\hline \multirow{2}{*}{ Senior Spring } & ME 430 Senior ME Lab II (3) & $1,2,3,4,5$ and 6 \\
\cline { 2 - 3 } & ME 412 Senior Project* & $1,2,3$ and 4 \\
\hline
\end{tabular}

*Experimentation is a component of the course

\section{Table 1: Design of Experiments Curriculum}

As outlined in Table 1, ME 420 provides a curriculum assessment point to ensure that these six components are executed on a focused thermal fluids experience to meet ME and ABET Criterion 3(b) program outcomes ${ }^{5}$ prior to the capstone experimental experiences in ME 430. This checkpoint in the curriculum in this upper division laboratory course ensures that students have acquired the tools and skills to support achievement of these outcomes through these six components. If any deficiencies are noted, the implementation of this curricula and its effective assessment strategy ensures that faculty are able to assess student outcomes in the area of experimental design through a closed loop corrective action and continuous improvement process, which facilitates making any adjustments in this case prior to the capstone laboratory experience, but in general at any point in the curriculum.

\section{Course Description and Structure}

The outcomes of ME 420 lab experience equip students to plan, conduct, and evaluate the results of measurement and testing of thermal-fluid systems as well as develop the capability to produce professional engineering reports. The basic theory and objective of each experiment, including the theory and application of thermal-fluid measurements and instrumentation, is presented in supporting lecture since the engineering science course is typically not concurrent with the lab. Students then apply and compare fundamental knowledge of heat transfer, thermodynamics and fluid mechanics to the design of experiments. In addition, students are given the opportunity to

"Proceedings of the 2005 American Society for Engineering Education Annual Conference \& Exposition Copyright (C) 2005, American Society for Engineering Education" 
continue their growth in teamwork skills. Given the facilities and equipment available to support the fall 2003 offering of the course, the following topics were covered:

- Engineering Report Writing

- Experimental Methods and Uncertainty

- Fluid Measurements and Instrumentation

- Pump Performance Characteristics

- Convective Heat Transfer Measurements

- Solar Energy Applications

- Thermodynamic Cycles

The overall course structure for fall 2003 is shown in Appendix A. In addition to the instructorled experiments and facility tours, student teams were required to execute a DBT project of their own choice. The unstructured nature of this project was well suited to capturing a range of students' interests and accommodating different learning styles. Students' mastery of the subject was enhanced with a creative and cooperative learning experience ${ }^{7}$. The course's multiple concurrent activities with concurrent deliverables required the individual student and student teams to effectively manage their time.

The deployment complexity of the course required considerable forethought, preparation, development, and implementation by the student teams to ensure a successful DBT experience ${ }^{6}$. In order to facilitate students' success in this open-ended DBT lab experience, the instructor developed a reasonably rigid project and deliverables schedule shown in Table 2.

\begin{tabular}{|l|c|}
\hline \multicolumn{1}{|c|}{ DBT Project Activity or Deliverable } & Project Schedule \\
\hline \hline DBT lab discussion, project deliverables and alternatives introduced & Week 4 \\
\hline $\begin{array}{l}\text { Alternate topics must be discussed with the instructor prior to this } \\
\text { date. Topic proposal with your priority list are due. }\end{array}$ & Week 5 \\
\hline DBT projects assigned. & Week 6 \\
\hline $\begin{array}{l}\text { Phase I of project plan due. Including a list of required supplies, test } \\
\text { equipment or instrumentation, and timeline. }\end{array}$ & Week 9 \\
\hline $\begin{array}{l}\text { Phase II of project plan due. Including objectives, theory, draft set up, } \\
\text { procedure, conditions to run experiment and updated list of supplies } \\
\text { and equipment. Status of week 9 equipment and supplies. }\end{array}$ & Week 11 \\
\hline DBT draft lab handout, instructor's notes, and data sheet/template. & Week 13 \\
\hline DBT final lab handout, instructor's notes, and data sheet/template. & Week 16 \\
\hline DBT demonstration & Exam Week \\
\hline Peer evaluation & Exam Week \\
\hline
\end{tabular}

Table 2: ME 420 DBT Project Activity and Deliverables

"Proceedings of the 2005 American Society for Engineering Education Annual Conference \& Exposition Copyright (C) 2005, American Society for Engineering Education" 
Adherence to the schedule and deliverables outlined in Table 2 kept the student teams on track to towards successful project completion. The project status and deliverable approach had been successfully used in other design project based professional courses in the ME curriculum.

From the outlined schedule, the DBT project was introduced to students at week 4 into the semester. In the fall 2003, three teams of four students each were given the following list of topics to select from, which were supportable with laboratory equipment infrastructure, or were encouraged to develop a unique topic within their lab teams. Only one team was allowed to select a topic, which was managed by the teams submitting a prioritize list of three topics for review and discussion with the instructor in week 5.

1. Natural Convection of Heat Sink Fin - Extended surfaces are used to enhance the heat transfer in a number of applications. In electronic cooling, "heat sinks" are used to transfer the waste heat from an electronic device. The design and testing of a single fin heat sink of various materials/lengths such that the tip temperature is the local ambient temperature is required.

2. Head losses in pipe systems (ELD System Upgrade) - Pipe networks are necessary for industrial, agricultural, municipal water supply and return systems. Losses must be accounted for in design of pipe systems.

3. Drag on an Object (Wind Tunnel Characterization) - Friction along the surface of an object produces drag forces opposite to the direction of flow. The drag force is a function of flow characteristics and physical characteristics of the object.

4. Local Minor Losses - Local losses are energy losses associated with an obstruction to flow, change in pipe cross-section, change in pipe characteristics, or change in flow direction.

5. Domestic Hot Water System - In concert with the Center for Advanced Solar Studies (CASS), assemble and characterize a solar energy domestic hot water system.

6. Forced Convection Heat Transfer - Study the effects of adjacent tubes on the heat transfer from a single tube in the array.

\section{Open Channel Flow - Meters and Phenomenon}

Weirs - Weirs are over-flow devices used to measure flow in open channels. Weirs must be calibrated to account for losses associated with flow over the weir.

Sluice Gate - A sluice gate is an underflow device used to control water surface elevations upstream and velocity downstream. When calibrated, a sluice gate can also be used as a flow-measuring device.

Hydraulic Jump - A hydraulic jump occurs when downstream flow is obstructed. A hydraulic jump is sometimes used to dissipate flow energy.

With this cohort of students, team selection was based on a thinking style preference assessment that was performed by the Hermann Brain Dominance Instrument ${ }^{\circ}$ (HBDI). The results of the

"Proceedings of the 2005 American Society for Engineering Education Annual Conference \& Exposition Copyright (C) 2005, American Society for Engineering Education" 
HBDI Survey indicate the degree of thinking preference for each student in the four quadrants: analytical, implementation, social and conceptual. Teams were formed with an effort to creating a group that possessed preferences in each of the four thinking style quadrants. This approach has been demonstrated in other professional component courses in the ME program curriculum to provide well-balanced teams.

These student teams, which developed a unique topic, are required to discuss with and obtain approval by the instructor prior to the project assignment deadline of week 6 . During this project review process, the instructor provided guidance to student teams through the requests to refine a proposed experiment or to narrow or broaden a project scope to ensure that the DBT project can be completed successfully and on time. Once these items were addressed, the project selection process was completed, and the student teams selected the following topics 2, 5 and 6 listed above.

Over ten weeks, the student teams designed, built and tested these experiments. Prior to starting this process, project plans, which included experimental objectives, complete theory, draft experiment set up, procedure, conditions used to run the experiment, list of supplies and equipment and a timeline, were required by week 11 . Instructor guided involvement continues after project assignment through this project planning process. The instructor monitors team performance through evaluation of project planning deliverables in Phase I and II, and notifies teams of any required corrective action. This monitoring and feedback process ensures that the student teams remain focused on project and team members' responsibilities, and on project scope creep not significantly altering project content or impacting the DBT project schedule. The instructor guides, but does not lead, teams in these areas ${ }^{6}$.

After project plans are evaluated and approved by the instructor with feedback, the execution of DBT project can then proceed. Student teams had four open project sessions to meet with team members and instructor, with the structured instructor-led lab experiences overlapping. All DBT demonstrations are performed during exam week. Student teams evaluate the performance of their peers during these demonstrations through the use of the evaluation sheet in Appendix C. Even though this experience takes place from a point of view of the student, who is less familiar with the role of instructors building a lab experience, students benefited through their participation by learning about other thermal fluids projects and by critical review of other work.

Each student team's overall DBT project grade includes these peer evaluation results together with the instructor's evaluation of the final DBT project documentation, demonstration and experimental test bed construction.

\section{Course Assessment and Lessons Learned}

Course assessment is an integral part of providing a continuously improving, quality education, and ensuring that the appropriate outcomes are being met through the course. Assessment is a different than evaluation. In evaluation, the student assesses how well the instructor delivered the content to the students; while in assessment, the students and instructor assess how well the goals of the course were achieved in terms of student learning and the student's ability to apply the learned skills and knowledge.

"Proceedings of the 2005 American Society for Engineering Education Annual Conference \& Exposition Copyright (C) 2005, American Society for Engineering Education" 
By the end of the course, the students will be able to:

1. Evaluate and apply methods of experimental measurement for thermal-fluid phenomena.

2. Document experimental results through clear, concise lab reports.

3. Provide an accurate evaluation of the uncertainty of experimental results.

4. Perform effectively as team members

The instructor assessed student performance on these outcomes is via their grades on six prelaboratory assignments, six laboratory reports of three formats: "long", "short" and "professional", which were also both team and individually assigned, three company/facility tours, and the independent laboratory experience, which reinforced the design, build, and test methodology of the curriculum. The laboratories were deployed in a matrix arrangement such that each team was working on a different laboratory during a given time period, and overlapping these laboratories are the activities associated with the DBT experience. Therefore, an appropriate level of independent student and team responsibility and overall complexity of the course deliverables was established for a senior level course.

The students used the student self-assessment survey given in Appendix B to determine the success of the course in enabling them to achieve the course outcomes, with a 0 indicating no mastery and 10 very proficient. The course goals are to provide students with initial fundamental experiences in the stated outcomes and a level of competence with these outcomes. The outcomes of the course reflect intended exposure to the appropriate measurement methods, principles for further study, and extension beyond the course materials via open-ended problem resolution, documentation of experimental results and proper reporting based on audience, and uncertainty analysis associated with laboratory investigation.

These assignments were matched with the course outcomes. A target score of 8.0 for all outcomes is proper, based on the grading methodology and first time preparation. Student performance and student self-assessment indicate that students achieved the course outcomes with a student assessment of Outcome 2 being slightly less than target, which is discussed below. Student assessment of Outcome 4 favorably supports the DBT experience through student perceived team effectiveness. Outcome 1 met the target score but did not have any perceived benefit by students; however, demonstration competence was reflected in evaluated reports. These outcomes will be monitored in future offerings to gage the impact of the DBT experience on course outcomes. The results of this student survey instrument and instructor course grade based assessment of the course outcomes are shown in Figure 2.

This is a first lab course in thermal fluid sciences for Mechanical Engineering students. The course is in evolutionary mode since it is a first time taught and was housed in ET laboratory facilities. The complexity of the deployment of the course was higher than expected for future offerings due to limited infrastructure (i.e., limited equipment and facilities) to support student laboratory experiences in the thermal fluid sciences. Anticipated larger student populations in the future will require infrastructure investment and possibly multiple sections of this course to reduce this complexity. 


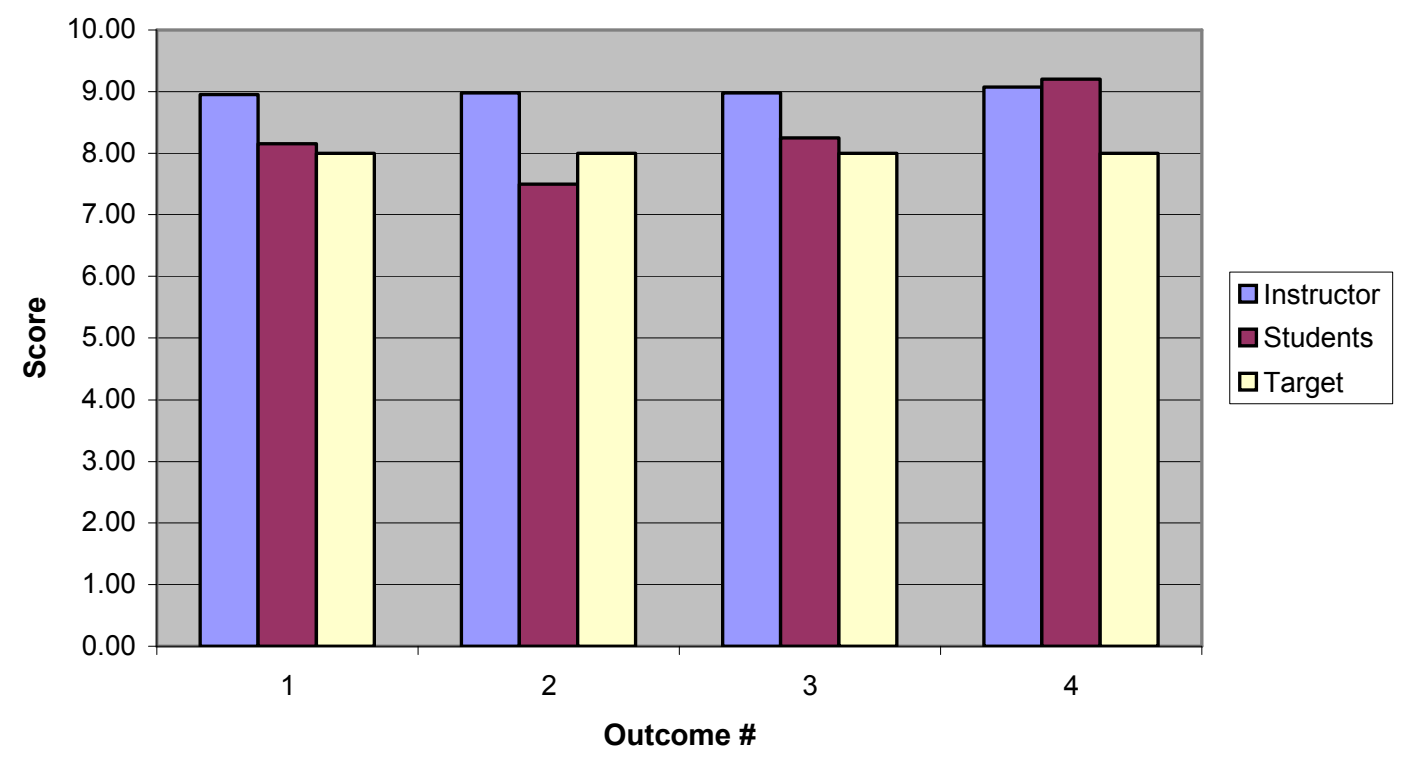

Figure 2: ME 420 Course Outcomes Assessment for Fall 2003

In addition to the numerical rating of each outcome by students, comments were also solicited on suggestions for improvements to achieve these outcomes. Comments were focused on two areas: the DBT experience and "long" report format requirements and quantity. Students indicated that the DBT experience was very effective; however, they indicated that the complexity of the schedule and its deliverables could have been supported by more in-class discussion, by identifying equipment needs earlier in the process and by earmarking additional funds to support equipment acquisition.

These two resource constraints, time and money, are encountered by all engineering professionals so this lesson was a valuable and unintended one. The report writing approach employed in the course required various formats, "long", "short" and "professional", expected by an engineering professional. Even though reporting of experimental results (component 6) is interwoven in the courses in the Design of Experiments Plan, it became apparent that additional effort in this area is needed earlier in the curriculum to reduce this student frustration and subsequent disconnect with course Outcome 2. The structure provided by the Design of Experiments Plan and the assessment methods employed in the semester faculty peer review of course effectiveness provides the close loop corrective action and continuous improvement process to make these adjustments.

\section{Summary}

A laboratory design experience, successful integrated into a traditional instructor-led laboratory course, has been demonstrated. In addition to the instructor-led thermodynamics, fluid mechanics and heat transfer experiments and facility tours, student teams were required to design, build and test (DBT) an experimental design project of their own choice. The unstructured nature of this project was well suited to capturing a range of students' interests and 
accommodating different learning styles. The complexity in the deployment of the course was driven by multiple concurrent activities with concurrent deliverables, which required the individual student and student teams to effectively time manage this complex deliverable matrix, and infrastructure limitations.

The DBT project is coordinated through the ME program Design of Experiments Plan and further supports the ME program's Professional Component Plan by requiring the use of engineering design with open-ended problems, integration of professional tools, and demonstration of professional communications. The Design of Experiments Plan provides a framework for coordinating the efforts of many lab courses, building upon previous lab work, assessing student progress, and adjusting lab coverage based on prior assessments to assure that Mechanical Engineering graduates of the program are capable experimental practitioners upon graduation.

The next offering of this course will be in the new engineering building so expansion and improvement in the laboratory infrastructure is expected with the continued inclusion of the DBT project as an enhancement to the design, build, and test methodology of the overall $\mathrm{ME}$ curriculum.

\section{Bibliography}

1. Schmaltz, K., Byrne, C., Choate, R. and Lenoir, J., "Integrated Professional Component Plan from Freshmen Experience to Senior Project," Proc. 2004 ASEE Annual Conference, Salt Lake City, UT.

2. Schmaltz, K. "Design of Experiments Plan with A Capstone Experimentation Course," Proc. of 2004 ASME International Mechanical Engineering Congress and Exposition, Anaheim, CA.

3. Holman, J.P., 2001, Experimental Methods for Engineers, McGraw-Hill, Boston.

4. Wheeler, A.J. and Ganji, A.R., 1996, Introduction to Engineering Experimentation, Prentice Hall, Englewood Cliffs, NJ.

5. 2004-05 Engineering Criteria, Accreditation Board for Engineering and Technology, Baltimore. (http://www.abet.org/criteria.html).

6. Saviz, C. and Schulz, K., "Learning Design in Lab," Proc. 2003 ASEE Annual Conference, Nashville, TN.

7. Lowman, J., Mastering the Techniques of Teaching, Jossey-Bass, San Francisco, 1995.

\section{ROBERT CHOATE}

Robert Choate teaches thermo-fluid and professional component courses in Mechanical Engineering at WKU, including the Sophomore Design, Junior Design and the Senior Project Capstone Design course sequence. Prior to teaching at WKU, he was a principal engineer for CMAC Design Corporation, designing and verifying thermal management solutions for telecommunication, data communication and information technology equipment.

\section{KEVIN SCHMALTZ}

Kevin Schmaltz teaches thermo-fluid and professional component courses in Mechanical Engineering at WKU, including the Freshman Experience course, Sophomore Design, Junior Design and the Senior Project Capstone Design course sequence. Prior to teaching at WKU, he was a project engineer for Shell Oil, designing and building oil and gas production facilities for offshore platforms in the Gulf of Mexico. 


\section{Appendix A: ME 420 Laboratory Course Outline}

\begin{tabular}{|c|c|c|}
\hline Week & Topics/Lecture and Lab Activities & Deliverables \\
\hline 1 & $\begin{array}{l}\text { LECTURE: Course Introduction, Engineering Report } \\
\text { Writing Methods, Fluid Mechanics Review }\end{array}$ & \\
\hline 2 & $\begin{array}{l}\text { LECTURE: Experimental Uncertainty LAB: Viscosity } \\
\text { Measurement - Two Methods }\end{array}$ & Prelab on Viscosity \\
\hline 3 & LECTURE and LAB: Halton Company Tour & Prelab on Halton Company Tour \\
\hline 4 & $\begin{array}{l}\text { LECTURE: DBT Project Introduction, Deliverables and } \\
\text { Alternatives; LAB: Flow Meter Measurements Lab }\end{array}$ & $\begin{array}{l}\text { Prelab on Flow Meters / Viscosity } \\
\text { Measurement Lab Report }\end{array}$ \\
\hline 5 & $\begin{array}{l}\text { LECTURE and LAB: WKU Steam Plant Tour and } \\
\text { Demonstration }\end{array}$ & $\begin{array}{l}\text { DBT Project Proposals and Selection / } \\
\text { Memo on Halton Company Tour }\end{array}$ \\
\hline 6 & $\begin{array}{l}\text { LECTURE: None; LAB: Centrifugal Pump Performance } \\
\text { Characterization Lab }\end{array}$ & $\begin{array}{l}\text { Prelab on Centrifugal Pump } \\
\text { Performance / Flow Meter } \\
\text { Measurement Lab Report }\end{array}$ \\
\hline 7 & Fall Break - No Class & \\
\hline 8 & $\begin{array}{l}\text { LECTURE: Thermodynamics Review LAB: Open Week } \\
\text { for DBT Projects }\end{array}$ & Centrifugal Pump Lab Report \\
\hline 9 & LECTURE: None; LAB: Open Week for DBT Projects & $\begin{array}{l}\text { Phase I Project Plan: DBT Project } \\
\text { Supplies/Equipment/Timeline }\end{array}$ \\
\hline 10 & $\begin{array}{l}\text { LECTURE: None; LAB: Vapor Compression Refrigeration } \\
\text { Lab }\end{array}$ & $\begin{array}{l}\text { Prelab on Vapor Compression } \\
\text { Refrigeration }\end{array}$ \\
\hline 11 & LECTURE: None; LAB: Open Week for DBT Projects & $\begin{array}{l}\text { Phase II Project Plan: DBT Project } \\
\text { Objectives/Theory/Procedure, etc. }\end{array}$ \\
\hline 12 & $\begin{array}{l}\text { LECTURE: None; LAB: Forced Convection Heat Transfer } \\
\text { - Single Tube and Tube Bundles }\end{array}$ & $\begin{array}{l}\text { Prelab on Forced Convection Heat } \\
\text { Transfer / Vapor Compression } \\
\text { Refrigeration Lab }\end{array}$ \\
\hline 13 & LECTURE and LAB: Open Week for DBT Projects & DBT Preliminary Documentation \\
\hline 14 & $\begin{array}{l}\text { LECTURE and LAB: WKU Steam Plant Data Collection } \\
\text { and Subsystem Efficiency Calculations }\end{array}$ & $\begin{array}{l}\text { Prelab on Steam Plant / Forced } \\
\text { Convection Heat Transfer Lab Report }\end{array}$ \\
\hline 15 & Thanksgiving Holiday - No Class & \\
\hline 16 & $\begin{array}{l}\text { LECTURE: Course Assessment LAB: Center for Advanced } \\
\text { Solar Studies (CASS) - Space Heating W/Solar Energy }\end{array}$ & $\begin{array}{l}\text { Steam Plant Lab Report/DBT Final } \\
\text { Documentation }\end{array}$ \\
\hline 17 & Exam Week - DBT Demonstrations & DBT Demonstrations \\
\hline
\end{tabular}




\section{Appendix B: ME 420 Student Self-Assessment Survey}

\section{Student Self-Assessment Survey}

Course assessment is an integral part of providing a quality education that endeavors to continuously improve instruction in all the courses. Assessment is a little different than evaluation. In evaluation, we are trying to gauge how well the instructor delivered the content to the students, while in assessment, we are trying to gauge how well we achieved our goals in terms of student learning and his/her ability to apply the learned skills and knowledge.

\section{Course: ME 420 Senior ME Lab}

Semester: Fall 2003

Please answer the following questions:

A. Review the course outcomes listed below and state if the course did or did not meet the course outcomes using a scale of 0 (can't do at all) to 10 (very comfortable doing). Please explain why it did or did not accomplish the outcomes.

1. Evaluate and apply methods of experimental measurement for thermal-fluid phenomena. Score:

2. Document experimental results through clear, concise lab reports.

Score:

3. Provide an accurate evaluation of the uncertainty of experimental results.

Score:

4. Perform effectively as team members

Score:

B. GIVEN A REASONABLE AMOUNT OF TIME, do you feel comfortable in approaching a general thermal fluid sciences laboratory problem where you must select the most appropriate solution technique, and then successfully apply that technique? Explain your response.

C. Do you have suggestions to improve the accomplishment of course outcomes? 
Appendix C: ME 420 DBT Demonstration Peer Evaluation Sheet

\section{DBT Demonstration Peer Evaluation ${ }^{6}$}

\section{REVIEWER:}

TEAM NAME:

Evaluate other teams on the following criteria using a scale of 1 (Poor) to 5 (Excellent):

- Quality of the Experiment Developed

Score:

- Quality of the Analysis and Findings of the Experiment

Score:

- Quality of the Presentation (Professionalism, clarity of explanations) Score:

- Complexity/Effort-Put-Forth/Completeness of the Project)

Score:

- Overall Assessment of the Project

Score:

- Additional Comments: 